\title{
Problems and Countermeasures Research on Development of Fuzhou's Cultural Tourism Resources \\ XIONG Wen-ping
}

Nanchang Normal University, Nanchang Jiangxi, China, 330029

Icshxwp@126.com

\begin{abstract}
Key Words: Fuzhou, eminent persons in history, cultural tourism, resource development, industrial upgrade
\end{abstract}

\begin{abstract}
Culture is the soul of tourism. As a famous "hometown of gifted scholars", Fuzhou has cultivated a galaxy of eminent persons in history and abundant cultural tourism resources. It can make people rich and protect the ecology to build the cultural tourism industry into a pillar industry of Fuzhou. On the basis of elaborating importance and existing problems, this paper has put forward mentality and countermeasures for the development of Fuzhou's cultural tourism resources.
\end{abstract}

\section{Significance of development of Fuzhou's cultural tourism resources}

Culture is the soul of tourism. The level and taste of tourism products, to a great extent, depends on their cultural connotation. Profound cultural deposits have become a decisive factor in the development of regional tourist economy [1]. The development trend of global tourism industry indicates that the degree of association and permeation between tourism and culture has been growing with each passing day. The competition among tourism enterprises has ascended to a cultural competition. Tourists are pursuing cultural enjoyment in their traveling. To satisfy the expectation and demands of the tourists and win the favor of tourists, tourist destinations must make a full use of their local cultural characteristics, endow local tourism products with more cultural values and connotation to enhance their attractiveness [2]. Known as a "hometown of gifted scholars", Fuzhou has witnessed a galaxy of great names in history such as Wang Anshi, a "reformer of the 11th century", Tang Xianzu, "opera sage of China" and "Oriental Shakespeare", Zeng Gong, "one of the Top Eight Great Writers of Tang and Song Dynasties", Lu Jiuyuan, a "great master of philosophy of the mind". As the cradle of Linchuan Culture, Fuzhou boasts abundant tangible cultural heritages, all of which are precious resources and have high development values. The significance of scientific and reasonable development of Fuzhou's cultural tourism resources is as follows,

\section{It's an objective requirement for solidifying the cultural soft power of Fuzhou}

Nowadays, cultural soft power has become a strong force for regional economic development. Enhancing cultural soft power has increasingly become an important way and strategic measure for enhancing comprehensive national strength [3]. For example, Tang Xianzu was a famous dramatist and writer in the history of China, who was honored as "Oriental Shakespeare" and "opera sage of China". He was praised for his pursuit of freedom, his persistence in people orientation, his guarding of real sentiments and independent personality. The culture of Tang Xianzu is a cultural brand of Fuzhou and its cultural essence represents the spirit of Fuzhou as a hometown of gifted scholars. His brilliant works such as Four Dreams of Linchuan are valuable wealth. Especially his Peony Pavilion is popular at home and abroad and shining with glory even today. By scientifically and reasonably developing these precious cultural resources and promoting and spreading the spirit of culture of Tang Xianzu, it will help enhance people's pride, cultural innovation, cohesiveness and cultural soft power of Fuzhou, the hometown of gifted scholars.

\section{It's an effective measure for actively protecting cultural heritages}

Culture is the soul of tourism. Cultural tourism has increasingly become an important part of 
tourism development of China. Many scholars have made valuable exploration into the tourism development of cultural heritages, believing that tourism development itself can protect and carry forward cultural heritages and is helpful for protection of cultural heritages and development of cultural industry[4,5]. It's an important means for Fuzhou to develop its economy by scientifically and reasonably developing its cultural heritages and focusing on development of cultural tourism industry. For example, Wenchangli is birthplace and burial site of Tang Xianzu, which is the old town of Fuzhou. Honored as the "historical archives" and "old town museum" of Fuzhou, Wenchangli gathers a lot of Jiangnan style architectures of the Ming and Qing dynasties, with cultural heritages such as Wenchang Bridge, Zhengjue Temple, Xiaoyi Bridge, Yulong Longevity Palace (Guild Hall of Fuzhou), many of which are cultural relic protection sites of the province and the city. By developing cultural tourism resources of Wenchangli, it can actively protect these precious cultural heritages. Fuzhou can build Wenchangli into a cultural tourism area complementary to tourist attraction of Dajue Mountain. Each year, China (Fuzhou) Tang Xianzu Art Festival can be held and become an important event for exhibiting and carrying forward the tangible and intangible cultural heritages of Fuzhou.

\section{It's an important means for promoting industrial upgrade of Fuzhou}

Fuzhou is blessed with a good ecological environment and was ranked top in the selection of "Oxygen Bars of China" in 2015. Fuzhou not only should develop its economy and make its people rich, but also should protect its ecological environment and do well in the construction of ecological civilization, which requires a solution to tackle the two tough issues and new industries to drive the industrial transformation and upgrade of Fuzhou. Fuzhou's cultural tourism industry boasts a huge development potential and can protect the ecological environment. Cultural tourism industry covers a wide range, boasts strong comprehensiveness and involves a multitude of fields and industries. The development of its cultural tourism industry will stimulate the development of its primary industry (agriculture), secondary industry (industry) and tertiary industry (service sector), form an industrial development cluster with its cultural tourism as the button and drive the economic development of Fuzhou. With Linchuan Culture represented by Culture of Tang Xianzu as the soul, with the good ecology of Fuzhou represented by Dajue Mountain as the foundation, with the tourism development of Fuzhou as an engine, the ecological and cultural tourism industry of Fuzhou will be built into its pillar industry and an important means for economic development and industrial upgrade of Fuzhou.

\section{Existing problems in the development of Fuzhou's cultural tourism resources}

\section{Fuzhou's cultural connotation is profound, but weak in deep exploration}

Fuzhou is rich in historical and cultural connotation, but lacks a deep exploration into cultural connotation. The development of some cultural tourist attractions of Fuzhou stops at a relatively low level of sightseeing, and has not achieved a dynamic expression with high-tech products and lacks projects for tourists to participate and experience. It only statically exhibits cultural works of famous persons, but lacks a deep exploration into the anecdotes and spirit of eminent persons in history; it simply exhibits some aspect of the culture, rather than makes a deep exploration and exhibition from several angles, serialize its culture and enrich its cultural connotation.

\section{Fuzhou has diversified cultures, but insufficient in efforts of integrating resources}

Fuzhou is rich in cultural resources such as opera culture, gifted youth culture, education culture, revolutionary culture and religious culture. However, cultural tourist attractions that have been developed up to date are mainly individual structures that are scattered. It's weak in efforts of integrating and developing cultural tourism resources. Today's cultural tourism is usually separate carriers such as separate development of single memorial hall, which has not well integrated resources and constructed an integral tourism segment of Fuzhou. Its administrative institutions 
have also not formed a concerted force. Only points of cultural tourism are developed, but the lines and plane of Fuzhou's cultural tourism have not been well integrated and developed. As a result, Fuzhou's cultural tourism projects are low in benefits and attract relatively few returned tourists.

\section{Fuzhou's infrastructure construction is weak, its environmental construction needs to be further strengthened, and the service level needs to be improved}

Fuzhou's infrastructure construction has developed to a certain extent, but not fast enough. The development of its traffic and supportive facilities for tourism is not very fast, which cannot satisfy demands of the tourists. The market environment, social security environment and hygiene environment of Fuzhou have been improved to a certain extent. However, its market environment and public security environment needs to be strengthened. The hygiene environment of some tourist attractions and scenic areas and restaurants needs to be improved. People employed in tourism of Fuzhou are different in quality, with service quality and efficiency to be further enhanced; the construction and development of its public service system is not very good and needs to be further strengthened. Quality and level of its public tourist service needs to be further improved. Phenomena of wanton felling of trees and discharging and emission of polluted water and gas still exist in Fuzhou, which has seriously disrupted the ecological environment of Fuzhou. For reasons such as influence of external culture, temptation of economic interest, lack of cultural protection and funds, cultural and ecological facilities of Fuzhou such as ancient architectures and ancient villages have been damaged and some intangible cultural heritages of Fuzhou have not been very well carried forward and protected.

\section{Mentality and countermeasures for development of Fuzhou's cultural tourism resources}

Based on analysis of this paper, development mentality for Fuzhou's cultural tourism resources is: With the development opportunity of building Fuzhou into a famous historical and cultural city and an ecological and cultural tourism area in the east of Jiangxi, with Culture of Tang Xianzu as the characteristic, we will blend culture and tourism, achieve a joint development and try to build Fuzhou into a cultural tourism area and build its cultural tourism industry into a pillar industry for its economic development.

\section{Make a deep exploration in cultural connotation and create a brand image}

We should make a deep exploration into cultural connotation, and enhance the depth and breadth of tourist attractions. Linchuan Culture boasts a profound connotation, rich resources, unique features, enjoying an important status in the cultural pattern of the province and the nation. We should fully integrate cultural elements with the tourism industry following a high start and a high standard based on revolutionary culture, opera culture, gifted youth culture, religious culture, ecological culture and education culture, thereby brightening tourism projects of Fuzhou with cultural charisma, strengthening tourism quality of Fuzhou with the connotation of Linchuan Culture and enhancing competitiveness of its tourism industry with cultural concept. We should actively create a tourism brand of Fuzhou with Linchuan Culture, try to explore new measures and means to promote construction of cultural tourism projects, enhance quality of cultural tourism with planning, optimize developing environment of cultural tourism, integrate resources to build boutique projects of cultural tourism, spread the cultural tourism brand of "hometown of Tang Xianzu", achieve a shift to intensification of the brand and promote the efforts of building Fuzhou into a famous historical and cultural city.

First of all, we should make a deep exploration into cultural connotation and create a festival brand. We should focus on building "Cultural and Art Festival of Tang Xianzu", strengthen the festival brand advantage of Fuzhou, cultivate it into a festival with national and international influence, thereby stimulating the growth of its income from tourism. Secondly, we should focus on implementing a strategy of driving with large projects. By building an opera town, we will build an opera capital of China; by building a romantic city, we will building a holy land of love. With these 
projects, we will build the cultural tourism area of Fuzhou into a national 5A tourist attraction.

\section{Optimize and integrate tourism resources, enhance overall competitiveness}

First of all, we should integrate tourism products. The core of development of cultural tourism resources is integrating cultural elements. We should "gather" scattered tourism factors into cultural tourism products with rich contents, prominent features and distinctive theme [6]. Linchuan Culture is the most substantial core culture of Fuzhou. We should unleash the role of cultural "transformation" and "integration", link up originally scattered tourist attractions and cultural elements, so that tourism development can be more deeper and wider and highlight its overall effect. Through integration based on realistic situation of scenic spots, Fuzhou shall develop special tourism products with distinctive themes and prominent features such as opera culture, celebrity tourism, religious worship, ecological sightseeing, revolutionary tourism and festival activities in accordance with requirements of "culture--brand--products" on the basis of scattered tourism resources such as opera, gifted youth culture, religious culture, ecological culture, revolutionary culture and festival activities.

Secondly, we should integrate travel routes. A reasonable travel route can effectively arouse the desire of tourists to travel. Generally speaking, the more elements involved in combination of travel routes, the greater the change will be, the more attractive the tourism resources will be and thus the higher the values of travel route will be [7]. In designing cultural tourism routes of Fuzhou, we should make a deep exploration into cultural connotation, highlight features and theme, integrate scattered cultural elements into travel routes with different themes and styles such as the travel to inspect and experience oxygen bar ecology of Fuzhou, hotspring health promotion holidaying travel, education and study travel, religious pilgrimage travel, travel to revolutionary areas, travel to ancient villages and towns and travel to experience the opera. We can build characteristics of each area of Fuzhou and diversified cultural tourism boutique products of the region into golden travel routes featuring brand products such as famous mountains, famous springs and famous persons.

Finally, we should integrate cultural industry and tourism industry. According to practice, the interaction and integration between the two industries is good for coordinated development of regional culture, economy and society, and fundamentally promote the development of the two industries [8]. The integration of the two industries is good for making a deep exploration into Linchuan culture, expanding the industrial space and optimizing industrial structure. Cultural tourism industry should blend cultural elements with six elements of tourism. On one hand, we should develop tourist attractions and scenic spots, infuse cultural connotation into tourism traffic, shopping, travel agencies and restaurants, develop themed culture and build a batch of themed tourist attractions, villages and towns, special blocks, hotels and restaurants and tourist commodities reflecting Linchuan Culture to expand the industrial chain and construct cultural tourism industrial clusters of Fuzhou. We should extend the industrial chain by including areas such as opera experiencing, performance, cultural creativity and publication. Combined with special resources of Fuzhou, we should promote special performances such as Nanfeng Nuo dance, Fuzhou tea picking opera and opera of Tang Xianzu, and develop special tourism such as oxygen bar ecology, hot spring health promotion and education and study tour; we should create film and TV plays related with famous persons of Fuzhou and develop the cultural creativity industry. We should roll out participation and experiencing activities of Fuzhou such as ceramics, oil painting, bamboo sculpture and bread making so that tourists can participate in and experience Linchuan Culture and want to stay in Fuzhou for a longer time.

\section{Strengthen infrastructure and environmental construction, enhance service quality}

Fuzhou is not very high in economic level and its infrastructure construction is not very complete. Therefore, funds shall be raised to step up the infrastructure construction of Fuzhou. Especially tourism service facilities and traffic facilities for tourist attractions and scenic spots shall be perfected, thereby strengthening the traffic accessibility to its cultural tourism and convenience of tourist service. 
We should create a good market environment, security environment of Fuzhou and improve its hygiene environment; enhance the civilization quality of citizens and make tourists feel the enthusiasm and warmth of Fuzhou people; enhance the professional quality and cultural quality of people employed by the tourism industry of Fuzhou, enhance their service quality and level; enhance the building of Fuzhou's public service system and public platform, and enhance the quality of public service for tourists; and strengthen the construction of tourism regulations of Fuzhou and regulate the behaviors of tourism employees.

We should protect the good ecological environment and cultural ecology of Fuzhou. The wonderful ecological environment and long-history Linchuan Culture of Fuzhou are the resource foundation for development of its cultural tourism as well as the environment for developing its cultural tourism. Without these resources, we will lose the source for development of its cultural tourism. Therefore, we should enhance protection of natural environment and cultural ecology of Fuzhou, coordinate the relationship between protection and development of natural ecology and cultural ecology, give consideration to economic, cultural and social benefits, protect cultural ecology to exhibit the long culture of Fuzhou and develop its cultural ecology tourism. We should strengthen protection and development of its cultural ecology by means of laws and administration.

\section{References:}

[1] Wang Yongqiang. On Development of Cultural Tourism Resources of Central Plain. Academic Journal of Henan University of Science and Technology: the social science edition, 2010, 28 (6): 84-86.

[2] Li Zhiliang. On Integration and Utilization of Historical and Cultural Tourism Resources of Chenzhou. Academic Journal of Party School of Municipal Party Committee of Urumchi, 2007, (1): $51-57$

[3] Yu Xuecai, Wang Jianmin. Protection of Cultural Heritages and Construction of Scenic Spots [M]. Beijing: Science Press, 2010.

[4] Zhou Wuzhong. A Win-win Situation of Cultural Heritage Protection and Tourism Development [J]. Hundred Schools in Arts, 2006, (7): 73-79.

[5] He Weijun, Zeng Dexian. Cultural Soft Power: Powerful Force for Regional Economic Development [N]. Guangming Daily, May 30, 2012.

[6] Ma Xiaodong, Zhai Renxiang. On Cultural Tourism Resources and Development--Taking Northern Jiangsu Area as Example [J]. Human Geography, 2001, 16 (6) 89-92.

[7] $\mathrm{Yu}$ Rongchun. Exploration of Strategies for Integration and Development of "Red, Green, Ancient" Tourism Resources of Ganzhou [J]. Enterprise Economy, 2007, (5): 120-122.

[8] Zhang Haiyan, Wang Zhongyun. Research on Integration and Development of Tourism Industry and Cultural Industry [J]. Resource Development and Market, 2010, 26 (4): 322-326. 